\title{
(RE)construindo Biologia: estágio supervisionado em regência no ensino remoto emergencial durante pandemia de covid-19 no Brasil
}

\author{
(RE)building Biology: supervised internship in conducting in remote emergency \\ teaching during the covid-19 pandemic in Brazil
}

\author{
Jamerson Santos Bandeira \\ Maria Danielle Araújo Mota ${ }^{2}$
}

\begin{abstract}
Resumo
O presente estudo tem como objetivo investigar quais são as dificuldades que professores e estudantes da disciplina de Biologia têm enfrentado durante a pandemia de COVID-19, no contexto de Ensino Remoto Emergencial de uma escola pública do estado de Alagoas. Também busca investigar quais são as possibilidades atenuantes para essas dificuldades, de acordo com as experiências vivenciadas durante as atividades escolares do componente curricular Estágio Supervisionado. Trata-se de um relato de experiência que, metodologicamente, configura-se como uma pesquisa de natureza exploratória, descritiva, de abordagem qualitativa, que considerou as experiências adquiridas durante a realização das atividades escolares do Estágio Supervisionado em regência para a disciplina de Biologia. Como resultado da pesquisa, ficou claro que, durante o Ensino Remoto Emergencial, os desafios pelos quais professores e estudantes da disciplina de Biologia têm passado consistem em problemas relacionados à desigualdade de acesso à internet e às diversas tecnologias digitais básicas. Também foi possível constatar deficiências na alfabetização tecnológica e tentativas frustradas de transpor metodologias de ensino centradas no professor e seu conteúdo para um contexto remoto. Neste sentido, a utilização de metodologias ativas de ensino mostrou ser uma possibilidade viável para atenuar essas dificuldades, promovendo motivação, engajamento e maior autonomia no processo de ensino-aprendizagem.
\end{abstract}

Palavras-chave: Ensino de Biologia. Estágio Supervisionado. Ensino remoto. Metodologias ativas. COVID-19.

\footnotetext{
Abstract

This study aims to investigate the difficulties that Biology teachers and students have

${ }^{1}$ Mestrando do Programa de Pós Graduação em Ensino de Ciências e Matemática (PPGECIM), Universidade Federal de Alagoas, Campus A. C. Simões. Atua na área de Ensino por Investigação. E-mail: jamerson.bandeira@im.ufal.br. Orcid: https://orcid.org/0000-0003-2362-6535

2 Professora da Universidade Federal de Alagoas (UFAL), Campus A.C Simões. Doutora e Mestre pelo Programa de Pós-Graduação em Educação Brasileira (PPGE) da Universidade Federal do Ceará (UFC), Eixo Ensino de Ciências. Licenciada em Ciências Biológicas pela Faculdade de Educação de Itapipoca (FACEDIUECE). Professora dos Programas: PPGECIM/ UFAL e PPGEFOP/UFAL. Atua na área de Formação de Professores de Ciências e Biologia e Ensino porinvestigação. E-mail: danielle.araujo@icbs.ufal.br Orcid: https://orcid.org/0000-0001-7305-647
} 


\section{-Revista de Iniciação à Docência, v.6, n.2, 2021- Publicação: dezembro, 2021 - ISSN 2525-4332}

faced during the COVID-19 pandemic, in the context of Emergency Remote Teaching in a public school in the state of Alagoas. It also seeks to investigate what are the mitigating possibilities for these difficulties, according to the experiences lived during the school activities of the Supervised Internship curriculum component. This is an experience report that, methodologically, configures itself as exploratory, descriptive research, with a qualitative approach, which considered the experiences acquired during the performance of school activities of the Supervised Internship in regency for the discipline of Biology. As a result of the research, it became clear that, during Emergency Remote Teaching, the challenges that Biology professors and students have gone through consist of problems related to the inequality of access to the internet and the various basic digital technologies. It was also possible to observe deficiencies in technological literacy and frustrated attempts to transpose teaching methodologies centered on the teacher and their content to a remote context. In this sense, the use of active teaching methodologies proved to be a viable possibility to alleviate these difficulties, promoting motivation, engagement, and greater autonomy in the teaching-learning process.

Keywords: Biology teaching. Supervised Internship. Remote teaching. Active methodologies. COVID-19.

\section{Introdução}

Como consequência do isolamento social, para a área da educação, decorrente da pandemia de COVID-19 houve notório e crescente desenvolvimento de demandas quanto às alternativas de continuidade para o processo de ensino e aprendizagem dos estudantes de licenciatura. Para atender a essas demandas, a modalidade de ensino remoto se mostrou a mais viável para o atual contexto de isolamento social, por meio das plataformas digitais (GONÇALVES; AVELINO, 2020).

Como alternativa possível para minimizar os impactos advindos do período sem aulas presenciais, vivenciado pelas escolas da rede pública do estado de Alagoas, surgiu, então, o Ensino Remoto Emergencial (ERE), alternativa de ensino em que as aulas ocorrem remotamente, de forma síncrona e assíncrona (COSTA, 2020).

É evidente que, para que haja continuidade na formação dos futuros professores, o Estágio Supervisionado, como componente curricular essencial para que sejam superadas as barreiras que separam a teoria da prática docente, precisa agregar as atividades escolares ao cotidiano escolar, o que se fazia presencialmente.

Apesar de tal correlação entre teoria e prática, proporcionada pelo Estágio Supervisionado, ser elemento característico desse componente curricular, mesmo em modalidade de ensino presencial, é preciso compreender que houve transformação do cotidiano escolar, da modalidade presencial para a remota.

Dessa forma, um novo Estágio Supervisionado em regência precisa ser estruturado, para que se atenda às necessidades formativas dos licenciandos, tendo em vista o novo mercado de trabalho docente remoto, moldado pela medida de isolamento 
social decorrente da pandemia do novo coronavírus, representada pela sigla COVID-19 (do inglês: Corona Virus Disease).

Para Souza e Ferreira (2020), o Estágio Supervisionado é um direito assistido ao licenciando, mesmo em um contexto de risco de vida como na pandemia de COVID-19. As autoras afirmam, ainda, que a profissão docente é capaz de produzir conhecimento nas interações entre professor e estudante, seja por meio remoto ou presencial.

Considerando tal capacidade, é, então, justificada a oferta do componente curricular Estágio Supervisionado, tendo em vista que tal oferta se configura como uma oportunidade de se pensar novo paradigma de formação para a profissão docente, permitindo a aquisição de novas habilidades e competências.

Nessa perspectiva, diante das adversidades que acometeram professores e estudantes da disciplina de Biologia em decorrência da adoção do Ensino Remoto Emergencial nas escolas públicas alagoanas, percebe-se a necessidade de se investigar, sob a perspectiva do estagiário, quais são os desafios que esses protagonistas da educação têm vivenciado. Também se faz necessário investigar o que compromete o desenvolvimento do processo de ensino-aprendizagem dos discentes, bem como quais são as possibilidades atenuantes para estes desafios.

As observações da realidade escolar na qual os estudantes e o professor supervisor deste Estágio Supervisionado em regência para a disciplina de Biologia estavam inseridos, serviram de motivação para a realização desta pesquisa. Nesse sentido, foram considerados os diversos desafios enfrentados no decorrer do estágio, relacionados à desigualdade de acesso à internet e às tecnologias básicas, bem como à desmotivação e à falta de engajamento por parte dos discentes.

A partir daí, faz-se a seguinte pergunta: quais são os desafios advindos da condição imposta pela alternativa de ERE para professores e estudantes da disciplina de Biologia da rede pública de ensino, bem como suas possibilidades atenuantes para que estes desafios sejam superados?

Nesse sentido, objetivou-se investigar quais são as dificuldades que professores e estudantes da disciplina de Biologia, de uma escola da rede pública do estado de Alagoas, têm enfrentado durante a pandemia no contexto de ensino remoto. Também se considerou como objetivo desta pesquisa investigar quais são as possibilidades atenuantes para essas dificuldades, de acordo com as experiências vivenciadas durante as atividades escolares do componente curricular Estágio Supervisionado em regência.

Portanto, este artigo é um relato de experiência das atividades escolares de Estágio Supervisionado em regência para o ensino de Biologia, durante modalidade de ERE em escola da rede pública do estado de Alagoas. 


\section{O Estágio Supervisionado no contexto da pandemia de COVID-19}

Desde março de 2020, quando declarado oficialmente pela Organização Mundial da Saúde (OMS)3 o estado de pandemia referente à COVID-19, o Brasil e demais países do mundo vêm adotando o isolamento social como medida sanitária necessária para a contenção da infecção pelo vírus SARS-CoV-2 (WHO, 2020).

Para Costa (2020), tais medidas de distanciamento tiveram impactos expressivos no setor educacional brasileiro. Nesse sentido, surge o Ensino Remoto Emergencial (ERE), que segundo a autora, trata-se de uma alternativa de ensino, mediada por Tecnologias Digitais de Informação e Comunicação (TDIC), em que a carga horária das disciplinas é dividida entre momentos síncronos e assíncronos, de atividades escolares.

Em abril de 2020, a fim de orientar os professores quanto ao ensino remoto, em contexto pandêmico, a Secretaria da Educação do Estado de Alagoas (SEDUC) publicou o Regime Especial de Atividades Escolares não Presenciais (REAENP). O documento apresentou diretrizes de como as disciplinas funcionariam de forma interdisciplinar, divididas por área, em um formato Laboratorial de Aprendizagem, tendo como parâmetro a Base Nacional Comum Curricular (BNCC) de 2017 e o Referencial Curricular de Alagoas (ReCAL) (ALAGOAS, 2020).

Somente em julho de 2020, o Ministério da Educação emitiu o parecer CNE/CP n: 11/2020 (BRASIL, 2020a), com as devidas orientações para a realização das atividades escolares presenciais e não presenciais durante a pandemia no Brasil, fazendo ressalvas quanto aos desafios da modalidade de ensino não presencial. Segundo o parecer, estes desafios estão relacionados, principalmente, à dificuldade que os professores têm em desenvolver aulas remotas por conta da acessibilidade dos estudantes à internet e tecnologias digitais básicas.

Apesar dos desafios de acessibilidade digital, além da falta de preparo formal para os profissionais de educação, em fevereiro de 2021, a SEDUC publicou, por meio de Diário Oficial, que as aulas para o ano letivo de 2021 na rede estadual de ensino deveriam voltar, de forma remota, no dia dez de março do mesmo ano (ALAGOAS, 2021).

Neste mesmo sentido, o Ministério da Educação, por meio do parecer $\mathrm{CNE} / \mathrm{CP} \mathrm{n}^{\circ} 5$ de 28 de abril de 2020 (BRASIL, 2020b), aprovou a continuidade dos Estágios Supervisionados para os cursos de licenciatura, permitindo a aproximação entre os estagiários e a escola por meio de plataformas tecnológicas.

Dessa forma, a modalidade remota emergencial do Estágio Supervisionado encontra amparo na utilização das TDIC, já antes utilizadas na modalidade de Ensino a Distância (EaD), desde que preconizadas pela Base Nacional Comum Curricular de 2018 (GONÇALVES; AVELINO, 2020).

\footnotetext{
${ }^{3}$ A Organização Mundial da Saúde (OMS) é uma agência das Nações Unidas, especializada em questões de saúde global, com o objetivo de garantir saúde e bem-estar para todos os seres humanos (WHO, 2020).
} 
É nesse contexto que o componente curricular de Estágio Supervisionado em regência é ofertado, visando à formação docente com experiência em ERE, em escolas públicas da rede estadual de Alagoas, proporcionando o desenvolvimento de competências e habilidades específicas para esse tipo de ensino.

Dessa forma, segundo Souza e Ferreira (2020), é possível a oferta do Estágio Supervisionado em modalidade remota, caracterizada pela regência em Ensino Médio, desde que haja aulas on-line para planejamento das atividades escolares, formação para uso do ambiente virtual por docentes e discentes e garantia de acesso e inclusão digital.

Segundo Chapani, Santos e Ribeiro (2016), é emergente a necessidade de inovações na formação dos professores de Ciências e Biologia, o que se reflete no crescimento de programas como o Programa Institucional de Bolsas de Iniciação à Docência (PIBID) e o Programa de Residência Pedagógica (PRP).

No entanto, tais inovações quanto à formação docente para um mercado de trabalho remoto, onde se exige maior proficiência na utilização das TDIC necessárias, além da capacidade de resolução de problemas quanto ao acesso às tecnologias digitais e à internet pelos estudantes, não foram contempladas pelo componente curricular em questão.

Nesse sentido, como discutido por Gonçalves e Avelino (2020), a oferta do componente curricular de Estágio Supervisionado em regência durante o ERE se caracteriza como de suma importância na aquisição de novas habilidades e competências pelos professores em formação.

Para o estado de Alagoas, as disciplinas escolares devem funcionar de forma interdisciplinar, divididas por área, em formato de Laboratório de Aprendizagem, como descrito no Guia de Implementação do REAENP, para os Laboratórios de Aprendizagem nas Unidades de Ensino da Rede Pública do estado (ALAGOAS, 2020).

É nesse contexto de ensino remoto interdisciplinar estadual que o estagiário, partindo do todo da área de Ciências da Natureza até chegar nas especificidades da Biologia, deve desenvolver suas atividades escolares, de forma a proporcionar maior experiência para um mercado de trabalho emergente, pautado nas TDIC. Dessa forma, tais tecnologias precisam ser reconhecidas como ferramentas essenciais no desenvolvimento do processo de ensino-aprendizagem dos estudantes em modalidade remota emergencial.

Para Pimenta e Lima (2014), é no processo de formação que se consolidam as opções e intenções da profissão. Para tanto, faz-se necessário que tal eixo curricular se caracterize como um espaço de reflexão, vivência e crítica, no qual a identidade do professor é gerada, construída e referida. Segundo as autoras, é no confronto com as representações e as demandas sociais, propiciado pelas vivências de estágio, que a identidade construída durante o processo de formação será reconhecida. 
Nesse sentido, esse novo contexto remoto emergencial se configura como fator de grande importância para a formação dos futuros docentes, contribuindo para a construção da identidade desse novo profissional da educação, muito mais familiarização com as TDIC que em tempos que antecederam a pandemia de COVID-19, a partir da reelaboração constante dos saberes.

\section{O Ensino Remoto Emergencial e a utilização das TDIC no ensino de Biologia}

A construção do conhecimento não é algo estático, mas se encontra em constante mudança, de acordo com o desenvolvimento cultural e tecnológico da sociedade ao longo dos anos. De acordo com Martins, Moura e Bernardo (2018), tal construção depende da coletividade e de seu meio sociocultural e, portanto, caracterizada pelas relações entre os seres sociais. Assim, o conhecimento não pode ser construído individualmente, mas depende das relações sociais que compõem seu entorno, influenciando e sendo influenciado pelos avanços tecnológicos e científicos (REGO, 1995).

A sociedade contemporânea vem sofrendo constantes mudanças e adaptações culturais econômicas e sociais em decorrência dos avanços tecnológicos e científicos, no qual a Biologia tem assumido papel protagonista, o que pode ser observado a partir das constantes descobertas científicas. Esse protagonismo perpassa não só o meio acadêmico, mas também alcança o público em geral e, consequentemente, a comunidade escolar, por meio das Tecnologias Digitais de Informação e Comunicação (PEDRANCINI et al, 2007).

Para Coelho, Silva e Pirovani (2020), devido ao crescente avanço tecnológico, os conhecimentos biológicos têm se tornado cada vez mais amplos e complexos, e, dessa forma, para que o professor tenha êxito em sala de aula, é preciso que ele pense em metodologias de ensino que sejam capazes de alfabetizar cientificamente os estudantes.

Nesse sentido, faz-se necessário considerar o contexto social e cultural tecnológico no qual estão inseridos esses estudantes, agora mais do que em qualquer outra época, tendo em vista os impactos e abruptas mudanças sofridas pelo sistema educacional brasileiro em decorrência da pandemia de COVID-19.

O mundo vive na era da imersão digital, em que a internet ocupa grande parte do tempo das pessoas, principalmente do jovem em idade escolar. Sobre todo e qualquer segmento social contemporâneo, é emergente um novo olhar para a comunicação informacional, que resulta na formação de novos hábitos comportamentais, voltados para o investimento tecnológico (GONÇALVES; AVELINO, 2020).

Segundo Lévy (1999), novos hábitos comportamentais contemporâneos definem novos conceitos e acepções para uma sociedade informacional, ao que ele chama de cibercultura. Para o autor, a cibercultura é o conjunto das técnicas materiais e intelectuais relacionadas às práticas, atitudes, modos de pensamento e valores sociais que, 
historicamente, e de forma gradual, são moldadas de acordo com o desenvolvimento cultural do ciberespaço.

Inseridos neste contexto de cibercultura, é notório que os estudantes contemporâneos, cercados pelas TDIC, não mudaram somente seu modo de falar, de se vestir ou de se expressar, como já observado nas diversas gerações anteriores. Houve uma mudança íngreme, de tal forma que se faz impossível voltar atrás. A esses estudantes, Prensky (2001) chama de nativos digitais.

Os impactos advindos do isolamento social causaram diversos problemas no sistema educacional alagoano. Os estudantes da rede estadual de ensino ficaram temporariamente sem atividades escolares formais, e tal hiato acabou por gerar desânimo nos discentes e professores, cujo resultado, de forma geral, segundo Vieira e Silva (2020) é uma acentuada desmotivação quanto a realização de atividades.

Para Oliveira e Souza (2020), a utilização de tecnologias digitais de ensino pode ser uma alternativa viável para atenuar alguns dos problemas do sistema de ensino brasileiro advindos da pandemia, relacionados à continuidade do ensino formal escolar. A partir daí, o ensino presencial precisou ser transposto para os meios digitais.

É nesse contexto que as TDIC, mais do que em contextos anteriores, assumem um papel crucial para o andamento e bom funcionamento do ERE, já que protagonizam como agentes de conexão relacional entre professores e estudantes. Nesse sentido, computadores, smartphones, tablets, entre outros, tornam-se de grande importância para a mediação na modalidade remota de ensino, quando existe acesso à internet pelos estudantes e professores.

Portanto, de acordo com Silva e Sales (2017), é imprescindível que discentes e docentes tenham proficiência na utilização das tecnologias disponíveis, o que é justificado, tendo em vista a importância do uso adequado dessas ferramentas tecnológicas durante esse período do sistema de educação brasileiro.

Se, por um lado, a adoção do ERE oportunizou a continuidade das atividades escolares formais para aqueles com acesso à internet e às tecnologias digitais básicas, por outro lado, trouxe à tona diversos desafios, relacionados às desigualdades no acesso à internet e a essas tecnologias. Tais desafios configuram situações adversas nos lares brasileiros, especialmente dos estudantes de escolas públicas do estado de Alagoas, ao que levanta questionamentos quanto o caráter inclusivo dessas tecnologias.

\section{Metodologia}

O presente estudo é um relato de experiência, cuja metodologia é de natureza exploratória, descritiva e de abordagem qualitativa. De acordo com Cavalcante e Lima (2012), um relato de experiência consiste em uma ferramenta metodológica, descritiva, que tem por objetivo apresentar uma reflexão sobre experiência vivida em determinado 


\section{-Revista de Iniciação à Docência, v.6, n.2, 2021- Publicação: dezembro, 2021 - ISSN 2525-4332}

âmbito de interesse.

Portanto, esta pesquisa tem por finalidade relatar, do ponto de vista do estagiário, quais são os desafios advindos da atual condição imposta pela adoção da alternativa de Ensino Remoto Emergencial para estudantes e professores da disciplina de Biologia em uma escola pública do estado de Alagoas.

O artigo também busca responder quais são as possibilidades para que tais desafios sejam atenuados, de acordo com as vivências resultantes das atividades escolares do componente de Estágio Supervisionado em regência, que se deu durante o primeiro semestre de 2020.

Quanto à disciplina de Biologia aqui mencionada, as atividades escolares envolveram três turmas de primeiro ano integral do Ensino Médio (primeiros anos 1, 2 e 3), que compartilharam do mesmo horário de aulas e da mesma sala virtual, na plataforma Google Meet, com uma carga horária de três horas semanais para cada turma.

A escola-campo desta pesquisa atende às demandas de estudantes oriundos de todo Centro da cidade de Rio Largo e arredores, região metropolitana em Alagoas. São ofertadas vagas para todos os anos do Ensino Médio, com quatro discentes de Educação Especial, 335 da Educação de Jovens, Adultos e Idosos (EJAI) e 425 do Ensino Médio regular.

Embora fosse possível contabilizar quantos estudantes participaram das aulas síncronas, por falta de articulação entre professores e gestor, a escola não soube informar qual o percentual de discentes que tiveram acesso à internet durante o estágio. Para aqueles sem acesso, foi disponibilizado um roteiro quinzenal, entregue presencialmente, no prédio da instituição.

O Laboratório de Aprendizagem trabalhado na disciplina de Biologia durante o estágio, como sugerido pelo REAENP, foi o de Desenvolvimento de Ideias Inovadoras, que tem o objetivo de conduzir os estudantes à compreensão sobre empreendedorismo e economia criativa (ALAGOAS, 2020).

As aulas foram organizadas por roteiros quinzenais, elaborados pelos professores de cada laboratório junto à coordenadora pedagógica da escola. Dessa forma, cada estudante recebia o roteiro quinzenal, via grupo de WhatsApp, com suas devidas orientações de estudo e avaliação. Um link para as aulas síncronas era sempre enviado semanalmente para o grupo de WhatsApp, e essa mesma rede social foi responsável por mediar as atividades assíncronas.

Foram 100 horas de atividades escolares de estágio remoto emergencial, oferecidos pelo curso de Licenciatura em Ciências Biológicas da Universidade Federal de Alagoas. A carga horária foi distribuída entre aulas síncronas e momentos assíncronos, reuniões de planejamento semanais, quinzenais e de reflexão para estabelecimento de diretrizes, e de momentos de estudo de referencial teórico. 


\section{Caracterização das aulas síncronas e momentos assíncronos}

As mediações em aula síncrona aconteceram uma vez por semana, pela plataforma Google Meet, e seguiram com conteúdos quinzenais, que foram, respectivamente: microbiologia, o atual cenário pandêmico, virologia geral, aspectos gerais do metabolismo e educação ambiental e conservação.

As mediações em momentos assíncronos também aconteceram uma vez por semana, por meio da rede social WhatsApp. Esses momentos consistiam em fóruns de discussão, onde o estudante tirava suas dúvidas sobre questões conceituais referentes ao conteúdo do roteiro, sobre os questionários quinzenais e avaliações investigativas e sobre as dificuldades quanto ao uso de tecnologias digitais para o bom andamento do ERE.

Os momentos assíncronos também consistiam em um estudo autodidata por parte do estudante, quando obtinham maior autonomia quando de seu próprio processo de desenvolvimento de ensino e aprendizagem. Durante esses momentos, professores e estagiários também eram consultados durante horários não estabelecidos previamente para as interações, mas tal atendimento só era dado para aqueles que só podiam naquele horário aleatório.

Durante os encontros síncronos, metodologias ativas de ensino foram utilizadas pelo professor supervisor e o estagiário, com o objetivo de promover uma maior participação e interação dos estudantes em aula. A ideia de metodologias ativas de ensino não é algo novo, mas vem sendo estudada desde os anos noventa, por meio de autores reconhecidos na área, como Bonwell e Eison (1991) e Barnes (1994).

Segundo Moran (2018), um dos maiores pesquisadores na área de metodologias de ensino, as metodologias ativas consistem em considerar o estudante como ser ativo de seu processo de ensino-aprendizagem. Dessa forma, o professor torna-se o mediador entre o saber científico de referência e o estudante, considerando seus aspectos culturais e sociais, e é o discente o principal responsável pela busca do conhecimento.

A primeira metodologia ativa utilizada durante momento síncrono foi a de Gamificação que, segundo Fardo (2013), um dos maiores pesquisadores brasileiros no assunto, trata-se da utilização de estratégias e técnicas dos games para envolver e motivar os estudantes, a fim de promover a aprendizagem e a resolução de problemas.

A utilização da metodologia de gamificação consistiu na aplicação de um jogo, cujo tema foi "Prisão microbiológica", no qual os estudantes estavam "presos" na sala de aula virtual e só poderiam sair se encontrassem a chave. Para encontrar a chave, a turma, que começava com cem pontos, tinha que trabalhar em conjunto para responder corretamente sete charadas sobre conceitos da microbiologia, cada charada em até dois minutos. Caso não respondessem no tempo, perderiam dez pontos e ganhariam mais um minuto para adivinhar a charada. 
Outra metodologia ativa utilizada durante os momentos síncronos foi a Sala de Aula Invertida que, segundo Maia e Furnival (2020), trata-se da aprendizagem onde o estudante se prepara antes do encontro presencial em sala, já que esta é dedicada somente ao aprofundamento de conceitos e discussão, além de atividades práticas.

Nesse sentido, após aula expositiva, de forma remota, sobre o assunto de virologia, foi requerido dos estudantes que encontrassem vídeos curtos de curiosidades sobre os vírus, sua morfologia, virulência e entre outros, para que, em um segundo momento, durante aula síncrona, tais vídeos fossem discutidos em sala de aula virtual.

Durante os momentos assíncronos, a metodologia ativa de Aprendizagem Baseada em Projeto ( $A B P$ ) também foi utilizada, por meio dos roteiros quinzenais. Segundo Barbosa e Moura (2013), a ABP tem o propósito de fazer com que os estudantes resolvam problemas com a colaboração dos colegas, onde o professor sugere um problema, cabendo aos estudantes criarem métodos e soluções para resolvê-lo.

A cada roteiro quinzenal, um projeto de ciências era requerido dos estudantes, como a cultura e observação de crescimento microbiano no período de uma semana, a construção de um filtro de água caseiro e a construção de um termômetro caseiro.

\section{Caracterização das reuniões de planejamento semanais, quinzenais e de reflexão}

A elaboração e desenvolvimento dos planos e atividades de estágio se deram em reuniões específicas semanais, mediadas pelo aplicativo de mensagens WhatsApp, com a presença do professor supervisor e do estagiário. Esses encontros consistiam na elaboração de planos de aula e material didático e tinham como objetivo estabelecer que atividades e metodologias seriam utilizadas durante a semana.

Para que fossem elaborados tais planos de ação e materiais didáticos, fora considerado a BNCC de 2018 como principal referencial teórico, além de referências específicas, a depender do conteúdo a ser abordado na semana. Também foram levadas em conta as questões socioculturais contemporâneas e o cotidiano dos estudantes do estágio.

Também foram realizados encontros coletivos de orientação, que consistiam em planejar e discutir os roteiros de aulas quinzenais, do Laboratório de Desenvolvimento de Ideias Inovadoras, e contavam com a participação de todos os professores de Ciências da Natureza que lecionavam nos primeiros e segundos anos do Ensino Médio da escolacampo. Tais encontros se deram de forma remota, por meio da plataforma Google Meet.

Ao final, o roteiro era organizado pela coordenadora pedagógica e distribuído para os estudantes, via WhatsApp para os que tinham acesso à internet, ou entregues pessoalmente no prédio da escola para aqueles sem acesso à internet. Além dos encontros coletivos de orientação para elaboração do roteiro, também houve reuniões 
entre professor supervisor e estagiário, sempre logo após as atividades síncronas e assíncronas com os estudantes.

Essas reuniões consistiam em reflexões sobre o desempenho e interação dos discentes em sala de aula virtual, bem como sobre suas dúvidas apresentadas durante os momentos assíncronos, objetivando diagnosticar os desafios do ensino remoto e fazer inferências quanto as possíveis soluções para a superação desses desafios.

\section{Resultados e discussão}

Quando do início das atividades escolares de Estágio Supervisionado em Regência, foi notório um certo desconforto e falta de manejo dos professores e estagiários durante as aulas síncronas e momentos de reunião. Tais anseios se justificam pelo fato de que o ensino formal, desenvolvido de forma remota e em caráter emergencial, é uma experiência extremamente nova e atípica (COSTA, 2020).

O sistema educacional vive um momento excepcional, uma nova modalidade de ensino no Brasil, o que, naturalmente, gera certa insegurança, não só para os estagiários, mas também para os docentes. Além disso, é imprescindível que se considere as desvantagens quanto a utilização das TDIC, seja por falta de familiaridade ou por dificuldade de acessar a essas tecnologias, por parte de estudantes e professores, o que é vital para o processo de ensino aprendizagem no contexto pandêmico atual (PIFFERO et al, 2020).

O caráter de novidade presente nessa modalidade remota emergencial trouxe à tona diversos desafios a serem enfrentados pelos estagiários, relacionados à falta de acesso à internet pelos estudantes (COSTA, 2020), além da falta de proficiência no uso das TDIC e falta de motivação e engajamento para a realização das atividades escolares. Ao que parece, os parâmetros educacionais foram desenvolvidos pensando muito mais em uma escola cercada por paredes e muito menos na interação educacional tecnológica de fato (SOUZA; FERREIRA, 2020).

A valorização do conhecimento historicamente construído pelos estudantes, o exercício de sua curiosidade, a valorização de suas manifestações artísticas e culturais, e entre outras, são habilidades da BNCC de 2018 que foram pensadas, originalmente, para serem desenvolvidas em ensino presencial (BRASIL, 2018), em uma sala de aula física, o que torna o desenvolvimento dessas habilidades em espaço virtual um grande desafio para o qual a maioria dos professores não estão preparados.

Portanto, atender às habilidades propostas pela BNCC de 2018 em uma modalidade de ensino tão nova mostrou ser um dos maiores desafios a serem enfrentados pelos professores e estudantes da disciplina de Biologia. Tais habilidades dependem da interação dos estudantes com seus pares e da interatividade dos mesmos, demonstrada em sala de aula (BRASIL, 2018). 
Esta mesma interatividade, elemento tão importante para o desenvolvimento do processo de ensino-aprendizagem dos discentes, encontra-se comprometida, em desigualdade decorrente das dificuldades de acesso à internet e às TDIC essenciais e pela falta de experiência no uso dessas tecnologias pelos estudantes e educadores.

O caráter emergencial dessa nova modalidade de ensino remoto também afetou o desenvolvimento dos estudantes em sala virtual, fato que ficou bem evidente durante as aulas síncronas, quando requisitado que falassem, expressando-se e interagindo uns com os outros, mas estes estavam sempre muito tímidos e acabavam participando pouco.

É possível inferir que este tipo de comportamento ocorre devido a esse cenário ainda ser estranho para os estudantes, o que pode passar uma certa impressão de que não exista seriedade ou formalidade nessa nova modalidade de ensino (COSTA, 2020). Esse fato também é evidenciado na evasão dos discentes, observada nas primeiras semanas de aula, que se mostrou ainda maior do que em modalidade presencial.

Essa deficiência motivacional, expressa pelos estudantes, também pode ser explicada pela falta de experiência no manejo das tecnologias básicas utilizadas em ensino remoto. Para Costa (2020), a falta de proficiência necessária no uso básico de TDIC utilizadas em ensino não presencial pelos estudantes, está intimamente relacionada com o desânimo dos educandos em modalidade remota.

Ninguém estava preparado para lidar com essa modalidade tão excepcional e de brusca mudança em que onde tudo parece novo e inconstante, é fato que ninguém estava preparado. Segundo Costa (2020), visando uma melhor adaptabilidade a esse novo "normal", existe, ainda, o desafio do desânimo dos discentes quando estes se desconectaram de suas interações sociais cotidianas de antes da pandemia, o sair da zona de conforto, quando do ensino centrado no professor e seu conteúdo, seu livro didático e seu quadro.

Quanto ao engajamento e motivação dos estudantes, ficou claro que, quando instigados a relatarem suas experiências quanto ao andamento dos projetos propostos pelos roteiros quinzenais, quase todos demonstraram interesse em compartilhar suas observações.

O que mais estimulava a interação e compartilhamento de experiências, eram as atividades com a utilização de metodologias ativas, como na abordagem do conteúdo por meio de Aprendizagem Baseada em Projeto ( $A B P$ ), quando do projeto de Ciências para crescimento microbiano, por exemplo. De fato, metodologias que restringem a participação ativa dos estudantes, como aula expositiva, parecem não surtir um efeito muito impactante no desenvolvimento do estudante durante esse período de aulas remotas.

Para Ribeiro (2017), em tempos de sala de aula sem limites físicos se faz necessário, por meio de metodologias ativas de ensino, promover a interatividade por 
meio de ferramentas que possibilitem a troca de informações e experiências entre os discentes e entre discente e docente.

Nesse sentido, a partir da utilização das metodologias ativas de ensino já citadas, houve melhora no desempenho dos estudantes. Esse fato ficou evidente ao ser observado o aumento significado na interação, motivação, engajamento e participação dos discentes em sala virtual durante a aplicação das metodologias ativas, em especial quando da aplicação da Gamificação em encontro síncrono.

Dessa forma, é possível inferir que a utilização dessas metodologias de ensino, associadas à uma maior proficiência na utilização das TDIC, configura-se como um caminho viável para o desenvolvimento do processo de ensino aprendizagem no atual contexto de Ensino Remoto Emergencial.

Amaral (2017) defende que a utilização das metodologias ativas favorece a autonomia do estudante na modalidade remota, estimulando na tomada de decisões individuais e coletivas, provenientes das atividades oriundas da prática social do discente. Tais benefícios da utilização dessas metodologias também puderam ser vistos nas turmas do estágio, a partir do aumento do rendimento escolar, do engajamento e motivação para realização das atividades escolares e da interatividade em sala de aula remota.

Em contrapartida, faz-se necessário compreender que, como estagiário em contexto de Ensino Remoto Emergencial, não basta saber a funcionalidade e a aplicabilidade de metodologias ativas (RIBEIRO, 2017). Para além de um ensino que priorize o protagonismo do estudante no seu próprio processo de ensino aprendizagem, este novo momento exige a aquisição de novas habilidades e competências pelos professores, principalmente no que diz respeito às TDIC.

Historicamente, o Estágio Supervisionado vem sofrendo modificações no perfil de formação dos professores. Sendo assim, fica claro que as demandas educacionais sofrem transformações, como mudaram vertiginosamente agora, e, com o passar dos anos, novas competências e habilidades precisam fazer parte da formação dos licenciandos (SOUZA; FERREIRA, 2020).

Também foi possível observar que, durante os momentos assíncronos, por meio de consulta via WhatsApp, os estudantes procuravam muito mais o estagiário do que o professor supervisor, o que talvez possa ser explicado pela maior familiaridade que o discente do Ensino Básico tem com o perfil de estudante atribuído ao estagiário.

Como bem colocado pelo parecer $\mathrm{CNE} / \mathrm{CP} \mathrm{n}^{\circ} 5$ do Ministério da Educação sobre as orientações educacionais para a realização de aulas e atividades pedagógicas presenciais e não presenciais no contexto da pandemia (BRASIL, 2020a), um dos maiores desafios da modalidade de ERE, e que também pode ser observado claramente nas turmas desse estágio, é a dificuldade que os professores têm em desenvolver aulas remotas por conta da acessibilidade dos estudantes à internet. 
Pensa-se sempre em aplicar metodologias ativas com o uso de Recursos Educacionais Abertos (REAs), como o Kahoot ou o Padlet, mas a realidade tecnológica dos discentes dificulta muito a realização desse tipo de atividade. Por causa das limitações quanto ao acesso à internet e recursos tecnológicos, além da falta de proficiência no manejo de TDIC, frequentemente opta-se por utilizar abordagem em forma de "roda" de conversa e aula expositiva.

Tal escolha se justifica pelo fato de que aplicar uma metodologia ativa em ensino remoto significa, quase sempre, associá-la a recursos tecnológicos que façam o intermédio entre o cotidiano do estudante e o conteúdo científico de referência, de forma a motivá-los, promovendo engajamento e autonomia em seu processo de ensinoaprendizagem (PIFFERO et al., 2020).

Fato é que a realidade de acessibilidade digital dos estudantes público-alvo desse estágio parece não ser contemplada em publicações sobre a aplicação de metodologias no contexto de ensino remoto. Alguns estudos parecem tratar de uma realidade em que todos os discentes possuem acesso a recursos didáticos tecnológicos e, concomitantemente, às atividades síncronas em sala virtual (SOUZA; FERREIRA, 2020). Portanto, faz-se necessário considerar que a aplicação de metodologias ativas associadas a TDIC pode ser um potencial fator de exclusão para a realidade dos estudantes de escolas públicas.

Quanto à forma de avaliar o desempenho dos estudantes, que consistiu na aplicação de questionários via Google Forms ou por meio do próprio roteiro quinzenal impresso, entregue aos sem acesso à internet, pareceu um tanto imprecisa e excludente.

A ideia de que ao responder o questionário, os professores e gestores vão conseguir fazer as devidas reflexões sobre a realidade dos discentes, bem como acompanhar o passo a passo da trajetória de construção de seus saberes, é de concepção precária, como colocado por Hoffmann (2014).

Para o estágio supervisionado em regência, na modalidade de Ensino Remoto Emergencial, ficou claro que não se pode simplesmente pensar a avaliação como uma adaptação daquilo que se fazia no ensino presencial em escola física (SOUZA, 2020).

De fato, faz-se necessário que todas as instituições repensem seus sistemas avaliativos, criando algo que funcione em sua realidade remota, já que pensar em avaliação, segundo Jesus (2019), é pensar em atividades que promovam a formação de um estudante reflexivo e autônomo, características importantes para os discentes em modalidade de ERE.

Outro grande desafio observado em sala e contemplado pelo parecer do Ministério da Educação já citado (BRASIL, 2020a), é que não existe um monitoramento organizado e bem embasado da aprendizagem dos estudantes durante as atividades não presenciais, o que torna necessário um maior aprofundamento sobre esse assunto. 
O REAENP defende que os meios virtuais podem ser utilizados desde que sejam observadas as possibilidades de acesso a esses meios pelos envolvidos no processo de ensino e aprendizagem (ALAGOAS, 2020). Esse acesso garantido a todos parece bastante utópico para a realidade das escolas públicas do estado em questão, o que se configura como o maior desafio para o ensino remoto em escolas da rede pública estadual.

O fato de a escola não saber informar quantos ou quais os discentes não têm acesso à internet, por simples falta de articulação entre a gestão da escola e os professores, se mostrou um agravante, pois, a partir dessa informação, poderia se traçar um planejamento mais eficaz na tentativa de mitigar os problemas advindos da falta de acesso à internet pelos estudantes.

Sabendo exatamente quais estudantes não têm esse acesso, seria possível, com o apoio financeiro das instâncias públicas responsáveis, a depender do trabalho e investimento da direção da escola, providenciar o acesso tanto à internet quanto às TDIC necessárias durante o ERE, reduzindo o problema à proficiência dos estudantes no uso dessas tecnologias.

\section{Considerações finais}

Quando do início desta pesquisa, constatou-se a importância de se investigar, sob a perspectiva do estagiário em regência, quais são os desafios e possibilidades atenuantes que professores e estudantes da disciplina de Biologia têm vivenciado durante a modalidade de Ensino Remoto Emergencial no contexto da pandemia de COVID-19.

Tal investigação baseou-se na tentativa de atenuar os desafios impostos aos estudantes e professores, a partir da constatação das adversidades advindas das experiências vividas durante realização das atividades escolares do componente curricular Estágio Supervisionado em regência, como a desigualdade de acesso à internet e tecnologias digitais básicas, além da falta de motivação e engajamento dos estudantes com relação às atividades escolares.

Diante disso, a pesquisa teve seu objetivo alcançado de forma positiva, já que, efetivamente, o trabalho conseguiu investigar, de acordo com as experiências resultantes das atividades escolares do componente curricular de Estágio Supervisionado em regência, quais os desafios pelos quais professores e estudantes da disciplina de Biologia, da escola em questão, têm passado.

Tais desafios consistem em problemas relacionados à desigualdade de acesso à internet e às diversas tecnologias digitais básicas, deficiências na alfabetização 


\section{-Revista de Iniciação à Docência, v.6, n.2, 2021- Publicação: dezembro, 2021 - ISSN 2525-4332}

tecnológica4 e tentativas frustradas de transpor metodologias de ensino voltadas ao professor e seu conteúdo como objeto central para um contexto remoto emergencial.

Também foi possível constatar que a utilização de metodologias ativas de ensino se configura como possibilidade viável e de relevante importância para atenuar tais adversidades sofridas pelos professores e estudantes da disciplina de Biologia.

A utilização dessas metodologias de ensino, além de possibilitarem maior motivação e engajamento por parte dos discentes quanto a realização de suas atividades escolares em momentos síncronos e assíncronos, também proporcionou maior autonomia em seu processo de ensino-aprendizagem.

O ensino remoto, da forma como está sendo construído nesse momento de mudanças, se configura como uma grande oportunidade. É em condições como essas, quando não limitados por uma escola de quatro paredes e, agora mais do que nunca, dependentes das TDIC para mediar tal processo, que geralmente se reflete sobre o uso de metodologias que retirem o professor conteudista do centro das atenções e faça do estudante o protagonista de seu processo de ensino-aprendizagem.

Portanto, esta pesquisa mostra a relevância de se investigar sobre os desafios e possibilidades atenuantes por que passam professores e estudantes da disciplina de Biologia em escolas públicas, já que são esses os mais afetados pela condição de ensino remoto, em decorrência das desigualdades de acesso à internet e às tecnologias digitais.

Além disso, a pesquisa retrata uma realidade comum à maioria das escolas públicas alagoanas, fornecendo um panorama para se entender como tem funcionado tal modalidade de ensino não presencial, permitindo fazer inferências quanto sua eficácia e limitações para o sistema educacional, pontos importantes que se sugere para pesquisas posteriores.

Esta pesquisa também se mostrou de grande importância para a formação de professores de Biologia, haja vista a necessidade de se formar um profissional que esteja apto para trabalhar de acordo com o contexto social, político e cultural de seus estudantes.

Dessa forma, o estágio em regência desenvolvido durante o atual contexto de pandemia é potencialmente capaz de proporcionar maior familiaridade com os desafios diários que o licenciando, como futuro professor, estará prestes a vivenciar, preparando-o para um novo mercado de trabalho emergente onde as TDIC se configuram como elementos essenciais no processo de ensino-aprendizagem dos estudantes.

Considera-se, aqui, como fator limitante, as restrições quanto a abrangência do público-alvo, pois somente três turmas dos primeiros anos do Ensino Médio de uma

\footnotetext{
${ }^{4}$ Para Lévy (1999), alfabetização tecnológica é um processo de construção social que consiste no acesso e na capacidade de se utilizar as tecnologias de forma consciente e crítica, conferindo uma maior capacidade ao alfabetizado de faze uma melhor leitura do meio sociocultural em que está inserido.
} 
escola específica foram consideradas. Portanto, para fins de avanços científicos quanto a superação das adversidades sofridas por professores e estudantes no contexto da pandemia de COVID-19, recomenda-se que se expanda a pesquisa, principalmente quanto a seu público-alvo.

No mais, espera-se que este artigo sirva como subsídio para trabalhos posteriores que objetivem encontrar soluções na tentativa de mitigar os desafios advindos da adoção do Ensino Remoto Emergencial pelo sistema educacional brasileiro.

\section{Referências}

ALAGOAS. Secretaria de Estado da Educação - SEDUC. Regime Especial de Atividades Escolares não Presenciais - REAENP. Laboratórios de Aprendizagem nas Unidades de Ensino da Rede Pública Estadual de Educação de Alagoas. Guia de implementação, abril de 2020. Disponível em: https://www.escolaweb.educacao.al.gov.br/pagina/regimeespecial-de-atividades-escolares-nao-presenciais. Acesso em: 3 mar. 2021.

AMARAL, Rita de Cássia Borges Magalhães. Prefácio. In: MACHADO, Andreia de Bem, et al. Práticas inovadoras em metodologias ativas. 1 ed. Florianópolis: Contexto Digital, 2017. p. 4-6. Disponível em: https://www.saojose.br/wpcontent/uploads/2018/09/praticas_inovadoras_em_metodologias_ativas.pdf. Acesso em: 3 jul. 2021.

BRASIL. Base Nacional Comum Curricular (BNCC). Educação é a Base. Brasília, MEC/CONSED/UNDIME, 2018. Disponível em: http://portal.mec.gov.br/conselho-nacionalde-educacao/base-nacional-comum-curricular-bncc. Acesso em: 3 mar. 2021.

BRASIL. Constituição da República Federativa do Brasil. Brasília: Planalto, 1988. Disponível em: www.planalto.gov.br. Acesso em: 6 fev. 2021.

BRASIL. Ministério da Educação. Parecer CNE/CP N: 11/2020, de 7 de julho de 2020a. Do parecer no tocante às orientações educacionais para a realização de aulas e atividades pedagógicas presenciais e não presenciais no contexto da pandemia. Relatora: Maria Helena Guimarães de Castro. Lex: SEI/MEC - 2142507 - Parecer CNE/CP, Distrito Federal, p. 1-26, 7 jul. 2020. Disponível em:

https://www.cnm.org.br/cms/images/stories/Links/09072020_Parecer_CNE_CP11_2020.pd f. Acesso em: 3 mar. 2021.

BRASIL. Ministério da Educação. Parecer CNE/CP n 5 de 28 de abril de 2020. Reorganização do Calendário Escolar e da possibilidade de cômputo de atividades não presenciais para fins de cumprimento da carga horária mínima anual, em razão da Pandemia da COVID-19. 2020b. Disponível em: http://www.mec.gov.br. Acesso em: $09 / 07 / 2021$.

CAVALCANTE, Bruna Luana Lima; LIMA, Uirassú Tupinambá Silva de. Relato de experiência de uma estudante de Enfermagem em um consultório especializado em tratamento de feridas. Journal of Nursing and Health, Pelotas, v. 2, n. 1, p. 94-103, 2012. Disponível em: https://periodicos.ufpel.edu.br/ojs2/index.php/enfermagem/article/view/3447/2832. Acesso em: 25 jun. 2021. 
CHAPANI, Daise Teresinha; SANTOS, Tamiles Batista; RIBEIRO, Vinícius Borges. Inovação pedagógica: possibilidades vislumbradas no contexto de um subprojeto de educação em ciências. Revista de Iniciação à Docência, [S. I.], v. 1, n. 1, p. 37-50, 2016. DOI: 10.22481/riduesb.v1i1.1591. Disponível em: https://periodicos2.uesb.br/index.php/rid/article/view/1591. Acesso em: 14 ago. 2021

COELHO, Fernanda Tesch; SILVA, Érica Duarte; PIROVANI, Juliana Castro Monteiro Percepção de estudantes do ensino médio de uma escola pública do Espírito Santo sobre o ensino de biologia: desejos e realidades. Olhares e Trilhas, Uberlândia, v. 22, n. 3, p. 381402, 2020. Disponível em: http://www.seer.ufu.br/index.php/olharesetrilhas/article/view/57134. Acesso em: 12 jul. 2021.

COSTA, Kátia Andréa Silva da. EAD, Ensino Híbrido e Ensino Remoto Emergencial: perspectivas metodológicas. Paraná: IFPR - DIRAC/PROENS, 2020. Disponível em: https://reitoria.ifpr.edu.br/wp-content/uploads/2020/09/EaD-Ensino-Hibrido-e-EnsinoDidatico-Emergencial.pdf. Acesso em: 5 mar. 2021.

FARDO, Marcelo Luis. A gamificação aplicada em ambientes de aprendizagem. Revista Novas Tecnologias na Educação, Porto Alegre, v. 11, n. 1, p. 1-9, 2013. Disponível em: https://www.seer.ufrgs.br/renote/article/view/41629/26409. Acesso em 20 out. 2021.

FRANZOLIN, Fernanda; TOLENTINO-NETO, Luiz Caldeira Brant; BIZZO, Nelio.

Generalizações que distanciam os conhecimentos dos livros didáticos das referências em genética. Genética na Escola, Santa Maria, v. 9, n. 2, p. 92-102, jan. 2014. ISSN: 1980-3540. Disponível em:

http://coral.ufsm.br/ideia/images/producao/RevtaGenEsc_9_02_Artigo03.pdf. Acesso em: 20 jun. 2021.

GONÇALVES, Natália Kneipp Ribeiro; AVELINO, Wagner Feitosa. Estágio supervisionado em educação no contexto da COVID-19. Boletim de conjuntura (BOCA). Boa Vista, v. 4, n. 10, p. 41-53, 2020. Disponível em:

https://revista.ufrr.br/boca/article/view/AvelinoGoncalves. Acesso em: 3 mai. 2021.

HOFFMANN, Jussara Maria Lerch. Avaliação mediadora: uma prática em construção da pré-escola à universidade. 34 ed. Porto Alegre: Editora Mediação, 2014. Disponível em: https://pt.scribd.com/doc/141241103/AVALIACAO-MEDIADORA-UMA-PRATICA-EMCONSTRUCAO-DA-PRE-ESCOLA-A-UNIVERSIDADE. Acesso em: 22 jun. 2021

JESUS, Rita Lee Lopes Vieira. Avaliação da aprendizagem: reflexões sobre um instrumento para o progresso na prática pedagógica. Revista de Iniciação à Docência, [S. l.], v. 3, n. 2, p. 22 - 31, 2019. DOI: 10.22481/rid-uesb.v3i2.5533. Disponível em: https://periodicos2.uesb.br/index.php/rid/article/view/5533. Acesso em: 14 ago. 2021.

LAGO, Nicole Cecchele. et al. Ensino remoto emergencial: investigação dos fatores de aprendizado na educação superior. Revista Ibero-Americana de Estudos em Educação, Araraquara, v. 16, n. 2, p. 391-406, 2021. Disponível em: https://periodicos.fclar.unesp.br/iberoamericana/article/view/14439. Acesso em: 2 jul. 2021. 
LÉVY, Pierre. Cibercultura. São Paulo. Editora 34, 1999. Disponível em: https://mundonativodigital.files.wordpress.com/2016/03/cibercultura-pierre-levy.pdf. Acesso em: 13 jul. 2021.

MAIA, Cristina MarchettiFURNIVAL, Ariadne Chloë Mary. A atuação do bibliotecário no ensino de Competência Informacional com o uso de Metodologias Ativas de ensino aprendizagem: uma pesquisa bibliográfica. Revista Brasileira de Biblioteconomia e Documentação, São Paulo, v. 16, p. 1-30, 2020. Disponível em: https://rbbd.febab.org.br/rbbd/article/view/1408. Acesso em: 5 out. 2021.

MARTINS, Evaneide Dourado; MOURA, Anaisa Alves; BERNARDO, Anacléa de Araújo. O processo de construção do conhecimento e os desafios do ensino-aprendizagem. Revista online de Política e Gestão Educacional. Araraquara, v.22, n.1, p. 410-423, 2018. Disponível em: https://periodicos.fclar.unesp.br/rpge/article/view/10731. Acesso em: 5 jul. 2021.

MORAN, José. Metodologias ativas para uma aprendizagem mais profunda. In: BACICH, L. et al. (org.) Metodologias ativas para uma educação inovadora: uma abordagem teóricoprática. 1 ed. Porto Alegre: Penso Editora, 2018. p. 7-38. Disponível em:

https://books.google.com.br/books?hl=pt-

BR\&Ir=\&id=TTY7DwAAQBAJ\&oi=fnd\&pg=PT21\&dq=(Moran)+and+(Bacich)+and+(2017)\&o ts=ohZZ7HsEnx\&sig=ZFM5gxHCugz7l_btU_aKeQ8D2po\#v=onepage\&q=(Moran)\%20and\% 20(Bacich)\%20and\%20(2017)\&f=false. Acesso em: 23 jul. 2021.

OLIVEIRA, Hudson do Vale; SOUZA, Francimeire Sales. Do conteúdo programático ao sistema de avaliação: reflexões educacionais em tempos de pandemia (COVID-19).

Boletim de conjuntura (BOCA). Boa Vista, v. 2, n. 5, p. 15-24, 2020. Disponível em: https://revista.ufrr.br/boca/article/view/OliveiraSouza. Acesso em: 23 jul. 2021

PAZ, Iolanda. Desafios do ensino remoto na pandemia. Revista Babel. São Paulo, 21 de junho de 2020. Disponível em: http://www.usp.br/cje/babel/?p=168. Acesso em: 4 jul. 2021.

PEDRANCINI, Vanessa Daiana et al. Ensino e aprendizagem de Biologia no ensino médio e a apropriação do saber científico e biotecnológico. Revista Electrónica de Enseñanza de las Ciencias. v. 6, n.2, p. 299-309, 2007. Disponível em:

http://reec.webs.uvigo.es/volumenes/volumen6/ART5_Vol6_N2.pdf. Acesso em: 19 jul. 2021.

PIFFERO, Eliane de Lourdes Fontana, et al. Metodologias ativas e o ensino de biologia: desafios e possibilidades no novo Ensino Médio. Ensino \& Pesquisa. União da Vitória, v.18, n. 2, p. 48-63, 2020. Disponível em:

http://periodicos.unespar.edu.br/index.php/ensinoepesquisa/article/view/3568. Acesso em: 23 abr. 2021.

PIMENTA, Selma Garrido; LIMA, Maria Socorro Lucema. Estágio e construção da identidade profissional docente. In: PIMENTA, S. G.; LIMA, M. S. L. Estágio e docência. 7 ed. São Paulo: Cortez Editora, 2014. p. 61-79.

PRENSKY, Marc. Digital natives, digital immigrants part 1 - On the horizon. MCB

University Press. Bingley, v.4, n. 10, p. 1-6. 2001. Disponível em:

https://www.marcprensky.com/writing/Prensky\%20-

\%20Digital\%20Natives,\%20Digital\%20Immigrants\%20-\%20Part1.pdf. Acesso em: 3 jul. 2021. 
REGO, Teresa Cristina. Vygotsky: Uma pesquisa histórico-cultural da educação. Petrópolis: Vozes, 1995. Disponível em:

https://www.academia.edu/31121677/VYGOTSKY_uma_perspectiva_hist\%C3\%B3rico_cultur al_da_educa\%C3\%A7\%C3\%A30. Acesso em 3 jul. 2021.

RIBEIRO, Ormezinda Maria. A produção de textos em uma sala de aula sem paredes: um desenho curricular em construção. In: MACHADO, Andreia de Bem, et al. Práticas

inovadoras em metodologias ativas. 1 ed. Florianópolis: Contexto Digital, 2017. p. 9-35.

Disponível em: https://www.saojose.br/wp-

content/uploads/2018/og/praticas_inovadoras_em_metodologias_ativas.pdf. Acesso em: 3 jul. 2021.

SILVA, João Batista da; SALES, Gilvandenys Leite. Gamificação aplicada no ensino de física: um estudo de caso no ensino de óptica geométrica. Acta Scientiae, v.19, n.5, p. 782798, 2017. Disponível em:

http://www.periodicos.ulbra.br/index.php/acta/article/view/3174. Acesso em: 3 jul. 2021.

SOUZA, E. M. F.; FERREIRA, L. G. Ensino remoto emergencial e o estágio supervisionado nos cursos de licenciatura no cenário da pandemia COVID 19. Revista Tempos e Espaços em Educação, v. 13, n. 32, p. 1-19, 2020. Disponível em:

https://seer.ufs.br/index.php/revtee/article/view/14290. Acesso em: 10 jul. 2021.

VIEIRA, Márcia de Freitas; SILVA, Carlos Manuel Seco da. A educação no contexto da pandemia de COVID-19: uma revisão sistemática de literatura. Revista Brasileira de Informática na Educação, v. 28, p. 1013-1031, 2020. Disponível em:

https://brie.org/pub/index.php/rbie/article/view/v28p1013. Acesso em: 5 jul. 2021.

WHO. World Health Organization. 2020. Disponível em:

https://www.who.int/emergencies/diseases/novel-coronavirus-2019. Acesso em: 8 jul. 2021. 